\section{RACISMO, XENOFOBIA, ANTISEMITISMO EN EL HORIZONTE DE LOS FLUJOS MIGRATORIOS. ENFOQUES TEÓRICOS Y TEORÍA CRÍTICA*}

\author{
José Antonio Zamora \\ Instituto de Filosofía \\ Centro de Ciencias Humanas y Sociales - CSIC
}

\section{RACISM, XENOPHOBIA, ANTISEMITISM ON THE HORIZON OF MIGRATION FLOWS: THEORETICAL APPROACHES AND CRITICAL THEORY}

\begin{abstract}
This article analyzes first the different interpretations of the racism and the xenophobia and their theoretical assumptions. Afterwards it shows their contributions as well as their insufficiencies, and puts them in relation to the theoretical assumptions in those that are based. Finally it tries to see in which measure the theory of the anti-semitism of the Critical Theory can be updated in this context in an enriching way.
\end{abstract}

KEY WORDS: Racism; xenophobia; antisemitism; immigration.

No resulta fácil escapar a las generalizaciones injustas o inexactas cuando se habla de las representaciones, las actitudes y los comportamientos xenófobos frente a la población inmigrante por parte de la población autóctona y de su vinculación con determinadas propuestas políticas. Del mismo modo que "los inmigrantes" son un colectivo plural, estratificado y culturalmente diferenciado, la población Ilamada "autóctona" también lo es. No existe un referente único de los discursos y las prácticas de dicha población en relación con los inmigrantes (Colectivo IOE 2005). Sin embargo, todas las propuestas teóricas sobre los prejuicios étnicos o racistas, desde las más clásicas (Allport 1954) a las más recientes (Tarman y Sears 2005; BonillaSilva 2006), afirman la existencia de un vínculo entre las crisis económicas y los conflictos de reparto asociadas a ellas, por un lado, y el aumento de la xenofobia, por otro (Balibar y Wallerstein 1991), lo que resulta bastante intranquilizante si tenemos en cuenta las dimensiones de la crisis actual (Cea D'Ancona 2008). El clima social y político que acompaña a las crisis se vuelve un campo propicio para la exteriorización de la xenofobia alimentada por los miedos y por la necesidad de imputar responsabilidades o de encontrar explicaciones sencillas a una situación
RESUMEN: Este artículo analiza primero las diferentes interpretaciones del racismo y la xenofobia y sus presupuestos teóricos. Después muestra tanto sus aportaciones como sus insuficiencias, y las pone en relación con los presupuestos teóricos en las que se basan. Finalmente trata de ver en qué medida la teoria del antisemitismo de la Teoría Crítica puede ser actualizada en este contexto de manera enriquecedora.

PALABRAS CLAVE: Racismo; xenofobia; antisemitismo; inmigración.

compleja, no menos que por la de imaginar salidas más o menos expeditivas a los complicados problemas que se derivan de ella.

Por otro lado, el fenómeno migratorio, en cuanto que es uno de los fenómenos clave de la nueva globalización, ha contribuido como pocos otros a una configuración multicultural de nuestras sociedades, que si bien siempre han sido más o menos plurales, ahora perciben con más evidencia la existencia de formas sociales, culturales y religiosas diversas y, al mismo tiempo, próximas (Zubero 2008; Silveira 2000). Esto tiene un efecto desestabilizador específico y un estrés identitario asociado a él que explicaría tanto la proyección de una supuesta homogeneidad cultural de la sociedad de acogida, como la identificación de los inmigrantes como una amenaza de dicha homogeneidad imaginada (Bralo y Morrinson 2005; Wieviorka 2003; Barcellona 2000). En nuestro ámbito, sobre todo a partir de los atentados de las Torres Gemelas, esa amenaza es percibida de modo especial en relación con los inmigrantes procedentes de países de mayorías musulmanas, lo que ha producido un clima de creciente islamofobia en toda Europa (Álvarez 2002). 
En este contexto de tensión entre tendencias de homogeneización cultural y afirmación reactiva de las identidades étnicas y religiosas, las migraciones han tenido un efecto deshomogeneizador sobre las sociedades receptoras. Términos tan en boga como "conflicto étnico", "multiculturalismo", "interculturalidad", "mestizaje", etc., reflejan entre otras cosas también la contribución de los grupos de inmigrantes cultural y étnicamente diferentes a la diversidad cultural imperante en las sociedades modernas avanzadas (Zapata-Barrero 2004). La discriminación legal, social y laboral que vive la mayoría de inmigrantes en los países donde residen ha ido reforzando cada vez más su resistencia a las pretensiones asimiladoras de las culturas dominantes. La demanda de reconocimiento de la identidad ya forma parte de las reivindicaciones irrenunciables de los inmigrantes frente a las sociedades receptoras, lo que en vez de ser reconocido por éstas como una oportunidad histórica de mutuo enriquecimiento se ha convertido en una fuente de conflictos. El interrogante que se plantea respecto a las relaciones interculturales dentro de las sociedades receptoras de inmigración es si la discriminación y el rechazo xenófobo se van a consolidar o será posible una integración social y un clima de diálogo intercultural presidido por actitudes abiertas hacia los "otros" diferentes.

Existen diferencias que en determinados momentos no tienen gran significado social ni determinan las relaciones de personas y grupos y que en nuevas situaciones se convierten en líneas divisorias mortales entre el "nosotros" y los "extraños". La colocación de la etiqueta de "extraño" por más que se trata de una atribución, de una construcción social más o menos artificial, puede tener consecuencias muy reales para los que son tipificados de esa manera. Entre los seres humanos, los grupos, las etnias, las culturas y las religiones siempre hay diferencias, pero también rasgos compartidos, semejanzas. La construcción del extraño supone la selección de algunas de esas diferencias como base para la autoidentificación de un sistema de acción, de modo que las semejanzas con los "extraños" se vuelven irrelevantes y esto de manera socialmente vinculante, lo que lleva, como ocurre hoy con la inmigración, a la creación de fobotipos (De Lucas 2002: 25).

Cuando todos los estudiosos del fenómeno migratorio señalan a la etnoestratificación del mercado de trabajo (de la que se derivan una serie de discriminaciones inaceptables para un Estado social de derecho), a las condiciones legales de acceso a nuestros países (que producen una insoportable e inhumana vulnerabilidad y precariedad jurídica y existencial), a la segregación y el aislamiento en zonas urbanas degradadas o fuera de los espacios normales de convivencia (que impiden el trato cotidiano, el conocimiento mutuo y la desactivación de los prejuicios), etc., como las verdaderas causas de la no integración, el discurso antimulticulturalista crea la figura del "inintegrable cultural" para buscar en las víctimas de la segregación la causa de la misma (Sartori 2002).

Los diferentes informes que presentan la realidad de la discriminación, la xenofobia y el racismo (Movimiento contra la intolerancia, SOS Racismo, Agencia Europea de Derechos Humanos) nos advierten de un aumento de estos fenómenos muy por encima de lo que registran los organismos de las administraciones públicas de los países europeos y ponen en guardia frente a una posible escalada de acciones violentas con esa motivación (European Union 2010a y 2010b; Movimiento contra la intolerancia 2008; SOS Racismo 2008). El hecho de que en este contexto grupos de individuos puedan ser considerados extraños, inferiores o peligrosos y, por tanto, objeto de discriminación o incluso de persecución y expulsión, despierta un interés que va más allá de los límites de la mera teoría. Y esto es asi porque dicha consideración puede tener efectos reales, y a veces fatales, sobre esos grupos. La movilización social y política de los prejuicios pone en peligro la dignidad, la integridad y la libertad de individuos concretos o de grupos enteros.

El intento de responder por medio de la clarificación discursiva y la argumentación, ya sea en el medio educativo o en otros medios, choca frecuentemente con las estructuras del prejuicio, que se muestran relativamente inmunes a esta manera de abordarlas. Ni siquiera la confrontación social durante décadas con la quiebra civilizatoria del nacionalsocialismo y el genocidio judío ha conseguido eliminar el potencial de amenaza del antisemitismo y el racismo. Dicha confrontación parece haber ayudado más bien a una especie de separación entre los discursos políticamente correctos en la esfera pública y un sustrato de prejuicios latente y persistente, que una vez que cambia el marco social, el discurso mediático o el contexto político, se exterioriza y comienza a organizarse (también políticamente). Por eso, si bien es cierto que se ha conseguido tomar con- 
ciencia de las estructuras del prejuicio y desacreditarlo, por otro lado asistimos a su estabilización como mecanismo de reacción defensiva y elemento de la identificación nacional. Estamos pues ante un problema fundamental para la integración de la población inmigrante.

Son muchas las investigaciones que analizan las estructuras del prejuicio desde una perspectiva de psicología social, de análisis del discurso o de teoría de la interacción. Salta a la vista que el marco teórico de los estudios empíricos, ya se realicen por medio de métodos cuantitativos o cualitativos 0 por una combinación de ambos, posee un efecto directo sobre los resultados 0 , al menos, sobre su interpretación. Hasta fecha relativamente reciente las aportaciones de la Teoría Crítica, cuyos trabajos reciben frecuentemente el calificativo de "clásicos", han sufrido una descalificación sumaria o se las ha considerado "superadas". Esto está cambiando (Volkov 2000; Braun/Ziege 2004; Ziege 2009). Sus investigaciones sobre los mecanismos sociales y psico-sociales del antisemistismo y el racismo están siendo recuperadas y desarrolladas actualmente por algunos proyectos de investigación.

Para captar el valor de estas aportaciones es preciso analizar primero las diferentes interpretaciones del racismo y la xenofobia y sus presupuestos teóricos. Después conviene mostrar tanto sus contribuciones como sus insuficiencias, así como ponerlas en relación con los presupuestos teóricos en las que se basan. Finalmente se trataría de ver en qué medida la teoría del antisemitismo de la Teoría Crítica puede ser actualizada en este contexto de manera enriquecedora. Esta indagación está presidida por la sospecha de que la disonancia entre los crecientes esfuerzos teóricos y prácticos antirracistas y la persistencia de las concepciones y las prácticas racistas está en relación con las limitaciones de los enfoques teóricos de la crítica del racismo y la xenofobia, por más que no se derive exclusivamente de ellos. Se trata, por tanto, de analizar hasta qué punto los fundamentos epistemológicos y metodológicos de ciertos enfoques críticos satisfacen realmente sus pretensiones críticas.

\section{AcLaraciones teRminológicas SOBRE EL RACISMO Y LA XENOFOBIA}

La primera dificultad a la que se enfrenta la realización de nuestro propósito está relacionada con la misma defi- nición de racismo, pues su concepto ha sufrido enormes variaciones en el curso del tiempo y se encuentra sobrecargado de connotaciones morales y políticas que lo harian teóricamente inservible a los ojos de muchos científicos sociales (Reemtsma 1991). Dependiendo de la definición que adoptemos puede convertirse en un fenómeno marginal o en la matriz de las estructuras de dominación social, en una realidad del pasado o en el nuevo eje de cristalización de los procesos de exclusión e inclusión, en un rasgo de grupos violentos de extrema derecha o en el centro de la socialización capitalista burguesa. Quizás sean estas dificultades las que han favorecido el auge de concepto de xenofobia. La cuestión es si un cambio de concepto elimina esas dificultades gracias a una especie de ilusionismo nominalista, frente al que había que tener todo tipo de precauciones, sobre todo si ese cambio sirve para poner el acento en el sentimiento subjetivo de pérdida de familiaridad con el entorno social y cultural por la presencia de una diversidad étnica y cultural percibida como extraña o de desestabilización de la identidad nacional de la mayoría social que iría asociada a esa pérdida. Sospecho que eso podría conducir a una antropologización del fenómeno y a convertirlo en una especie de constante de la condición humana que precede a cualquier experiencia social e histórica: una actitud negativa frente lo "extraño" común a todos los tiempos y todos los grupos sociales. Además, bajo estas premisas sería muy difícil escapar a una fijación positivista del extraño, que se convertiría en una realidad dada por existente como condición de la reacción, lo que dificultaría tanto el análisis de los procesos de la producción social del extraño como su cuestionamiento.

En efecto, uno de los problemas que plantea una definición del racismo es que parece obligar a presuponer aquello cuya existencia se pretende cuestionar. Como señala R. Miles, "no hay 'razas' y por lo tanto tampoco 'relaciones raciales'. Sólo hay una creencia de que existen tales cosas, una creencia que es utilizada por algunos grupos sociales para la construcción en el pensamiento de un Otro (y por lo tanto, del Sí mismo) como preludio de la exclusión y la dominación, y por otros grupos sociales para definir la identidad propia (y por lo tanto para la construcción de un otro) como un medio para resistir a la exclusión. Por lo tanto, si ha de usarse, la idea de 'raza' debe ser utilizada sólo para referirse de manera descriptiva a tales usos de la idea de 'raza'" (Miles 1993, 42). Miles utiliza el concepto de racialización para subrayar que la "construcción de la 
raza" es la condición que hace posible hablar de racismo, construcción que pasa por la atribución de significación a objetos y características previamente seleccionados. Se trata de un proceso de naturalización y esencialización de los grupos sociales que permite establecer una correspondencia entre determinados rasgos fenotípicos y cualidades positivas o negativas. Sobre la base de esta racialiazación se regula el acceso a los recursos materiales y simbólicos que produce la sociedad. De esta manera la praxis ideológica del racismo transforma el cuerpo en soporte de significaciones que actúan como signos de posicionamiento y estratificación sociales.

Esto permitiría al racismo tener una enorme flexibilidad para establecer vinculaciones variables con las cambiantes estructuras sociales y con las diferentes relaciones de dominación, así como servirse de las más variadas representaciones, aspecto especialmente resaltado por Stuart Hall (1978, 26; 1996, 435). Para este autor, la clave está en la imbricación de la construcción de significaciones con las estructuras de poder (Hall 1980). Apoyado en el concepto foucaultiano de "discurso", en el que quedan recogidos tanto los aspectos ideológicos como aquellos relativos a las praxis sociales, S. Hall Ilama la atención sobre una transformación de los discursos racistas en la actualidad, en los que la cultura ha sustituido al concepto biológico de raza (Hall, 1989). En realidad se trata de un cambio que acompañó la desaprobación social del racismo nazi en Europa (Adorno 1955b, 277) y los procesos de descolonización (Fanon 1961). El "racismo cultural" (Said 1993) o "racismo diferencialista" (Taguieff 1991) realiza el mismo proceso de esencialización y cosificación, pero ahora con las características sociales y culturales. La jerarquización racial es sustituida por la incompatibilidad de las diferentes formas culturales o pervive en las exigencias de asimilación a la cultura de la mayoría, a veces también bajo el manto de una oferta de integración. E. Balibar habla en un sentido parecido de "neorracismo" como un verdadero "fenómeno social total", que

"se inscribe en prácticas (formas de violencia, de desprecio, de intolerancia, de humillación, de explotación), discursos y representaciones que son otros tantos desarrollos intelectuales del fantasma de profilaxis o de segregación (necesidad de purificar el cuerpo social, de preservar la identidad del 'yo', del 'nosotros', ante cualquier perspectiva de promiscuidad, de mestizaje, de invasión), y que se articulan en torno a estigmas de la alteridad (apellido, color de la piel, prácticas religiosas)" (Balibar/Wallerstein 1991, 32).

Este carácter polivalente del racismo y la xenofobia les permite ser al mismo tiempo factores de reforzamiento de la identificación con el propio grupo, de la adaptación al orden vigente en él y del sometimiento a los mecanismos de reproducción de las relaciones de dominación, por un lado, y del rechazo de los señalados con extraños, de la discriminación y la exclusión de los otros en el acceso a los recursos materiales y simbólicos, de la jerarquización y explotación de los que son considerados inferiores, por otro. Bien entendido que ambos reforzamientos se implican mutuamente.

\section{ENFOQUES TEÓRICOS: DE LA PSICOLOGÍA SOCIAL AL ANÁLISIS DEL DISCURSO}

Después de esta aproximación al concepto de racismo, vamos a analizar a continuación diferentes enfoques en la explicación de este fenómeno. Ciertamente resulta casi imposible encontrar modelos explicativos en estado puro. Lo habitual es encontrar más de un elemento teórico y, por tanto, explicaciones mixtas, lo cual no impide identificar acentos y prioridades. Lo que buscamos ahora es diferenciar esos modelos para poder analizar sus virtualidades e insuficiencias.

\section{a) La investigación psicosocial sobre los prejuicios}

El concepto psicosocial de prejuicio se basa en la categoría de actitud considerada como una disposición para un determinado comportamiento en la que se aúnan dimensiones cognitivas, emocionales y de impulso a la acción. G. W. Allport (1954), uno de los pioneros en el estudio de los prejuicios, define el prejuicio étnico como una antipatía basada en una generalización errónea y rígida respecto a un individuo o un grupo que convierte determinados rasgos visuales en estímulo para la atribución de un perfil específico de carácter proyectivo. La clave para la existencia de esta antipatía habría que buscarla en una socialización deficiente y en los procesos psicodinámicos de los individuos que son sus portadores. Dichos procesos se encuentran dominados por mecanismos característicos como la identificación de chivos expiatorios o el vuelco de 
la frustración en agresión. Una vez adquiridos en las fases tempranas de desarrollo, los prejuicios se mantienen relativamente estables y orientan la percepción de la realidad y el comportamiento.

Junto a la prioridad que este enfoque concede a la psicología individual, por mucho que incorpore aspectos de relación intergrupal, resulta reconocible en este enfoque también una tendencia antropologizante que convierte las generalizaciones y la animadversión en relación a los grupos considerados extraños y opuestos en una propiedad del comportamiento humano en general (Memmi 1982) que sería explotada por el racismo. Sin negar los contextos sociales, económicos o políticos y su impacto amortiguador o pontenciador de los prejuicios, la investigación psicosocial pone el acento en los procesos psicodinámicos. Los mecanismos que operan en esos procesos son la disociación (de estados del yo impúdicos o mal vistos) y la proyección (de las propias insuficiencias y fracasos). El racismo cumpliria la función de permitir la transferencia de las propias frustraciones a los objetos del rechazo o la agresión. La incapacidad para desentrañar el origen de dichas frustraciones en la experiencia y de interpretarlas con sentido lleva a racistas y xenófobos a imputárselas a individuos y grupos que actúan de chivos expiatorios. Este mecanismo actuaría a modo de protección frente a la percepción de la propia inseguridad y miedo.

Pero, ¿por qué esta dificultad para la reflexión sobre la propia experiencia o para enfrentarse racionalmente a los miedos e inseguridades? Desde el punto de vista psicoanalítico, el racismo sería un síntoma de trastornos cognitivos y afectivos ocurridos en la infancia. Léon Poliakov (1976), por ejemplo, atribuye la apropiación de las teorías racistas por parte de los individuos a la capacidad que ellas poseen para dar satisfacción a los impulsos desconocidos y ocultos que han sido reprimidos y por tanto desplazados al inconsciente. La evolución afectiva del niño, la separación de la madre, el descubrimiento y la aceptación de los roles sexuales, etc., pasa por asumir la propia incompletud y por despedirse de la ilusión de omnipotencia. El deseo de recuperar la omnipotencia soñada debe ser reprimido y sometido a una prohibición. La negación de la castración y la voluntad de omnipotencia representan los impulsos básicos del juego de fuerzas psíquico-afectivas que se manifiesta en el racismo. El extraño aparece como una amenaza al deseo de omnipotencia reprimido. A través de la proyección de los propios impulsos sobre el extraño se legitima para el racista su segregación y rechazo. El extraño se convierte en pantalla de proyección de los propios deseos frustrados y reprimidos. Ésta sería la razón de que sus juicios se muestren tan resistentes, cuando no inmunes, al argumento racional.

A estas reflexiones sobre los vínculos del prejuicio racista con la deficiente resolución de los conflictos psicodinámicos en la infancia se unen aquéllas basadas en la teoría de la socialización que ponen el acento en los conflictos propios de la adolescencia. El concepto psicoanalítico que resulta pertinente aquí es el de regresión, que apunta a la insuficiente formación en los adultos de los mecanismos de elaboración de las tensiones y amenazas y, por tanto, al recurso a modelos infantiles de proyección, disociación e idealización, odio y agresión. El desplazamiento hacia un objeto exterior de los impulsos y deseos conflictivos produce alivio y posibilita orientación. El yo amenazado y desorientado se ve así reforzado por la identificación con figuras paternas idealizadas. De este modo, el racismo puede considerarse un síntoma de la insuficiente constitución de una identidad autónoma. Que en la coyuntura actual, caracterizada por la intensificación de la erosión social que acompaña a los procesos de modernización desbocada, se produzca un repunte del racismo no haría sino confirmar que estamos ante una crisis de orientación que afecta de modo especial a las personas con una identidad debilitada.

Frente a los enfoques de psicología social centrados en el análisis de los procesos psicodinámicos de los individuos como clave de interpretación del racismo y la xenofobia, cristaliza en los años ochenta otra línea de investigación centrada en los procesos de formación de los grupos y del sesgo endogrupo/exogrupo en la formación de la identidad social, tal como había sido propuesto por el Social Identity Approach (Tajfel/Turner 1986; Turner 1990). La clasificación y categorización de las personas, producto de los procesos de diferenciación intergrupales, serían las responsables de la formación de los prejuicios. Estos procesos de diferenciación formarian parte esencial de la formación de los grupos, formación que a su vez sería lo que posibilita y determina la identidad social de los individuos. Por medio de las categorizaciones los individuos pueden manejar la complejidad de su mundo de vida y encontrar un marco de referencia en el que situar su autocomprensión. El 
sesgo endogrupo/exogrupo pone de relieve que no existe identificación sin diferenciación y ésta tampoco existe sin comparación intergrupal. Es aquí donde cumplen su función los prejuicios y estereotipos. La pertenencia al grupo motiva a desarrollar una imagen positiva del propio grupo y estereotipos negativos de los exogrupos. La identidad social se ve reforzada por los prejuicios y los estereotipos, que se exteriorizan en el momento que los individuos perciben una amenaza a su identidad social o surgen conflictos de intereses entre diferentes grupos sociales.

\section{b) Análisis del discurso y racismo}

Un enfoque diferente al del análisis psicosocial de los prejuicios es el que ofrece el análisis del discurso y la crítica de las ideologías. Lo social no aparece aquí como mero contexto condicionante. El racismo y la xenofobia son fenómenos constitutivamente sociales, por eso el punto de mira ha de ponerse en el conjunto de la sociedad y no en las conciencias individuales. En este sentido las categorías de las que se sirven son construcciones sociales que permiten la exclusión material y simbólica de determinados individuos y colectivos. Dichas construcciones expresan luchas y conflictos y son modificadas por ellos. Por eso, existe una pluralidad cambiante de representaciones que se modifican con la dinámica social (Hall 1989). El discurso racista ni se puede desvincular de otros discursos discriminadores ni de las complejas relaciones de poder en que está inscrita su producción (Klinger/Knapp 2008).

Cuando hablamos de complejas relaciones de poder estamos diciendo que para el análisis del discurso de corte postestructuralista ha quedado superada una exclusiva determinación económica de la así llamada superestructura ideológica. No existen prioridades entre las diferentes formas de poder. Tanto el racismo como las relaciones de género o las relaciones de clase son construcciones sociales a través de las que están mediadas las estructuras de poder desde las que se regula y controla el acceso a los recursos materiales y simbólicos producidos por la sociedad o la exclusión de los mismos. Por otra parte, el análisis del discurso exige atender también a los cambios históricos y sus efectos sobre la construcción social de la diferencia, la desigualdad y la dominación. Esto significa tener en cuenta de qué manera los nuevos flujos migratorios dentro de los procesos de globalización económica y cultural han transformado multiculturalmente nuestras sociedades y originado nuevas formas de articulación del racismo. Los autores mencionados más arriba -E. Balibar, S. Halls o R. Miles- subrayan de manera especial esas transformaciones que en buena medida han dejado atrás al racismo biologicista clásico.

La atención a las transformaciones históricas del fenómeno "racismo" obliga a plantearse de manera inevitable su relación no sólo con las estructuras de poder actuales, sino también con los procesos sociales más determinantes de la configuración actual de dichas estructuras. En este sentido, Z. Bauman ha analizado los vínculos entre modernidad, racismo y exterminio judío y defendido la tesis de que el racismo constituye una forma de ingeniería social específicamente moderna. "Según este concepto de ingeniería social, es decir, un trabajo con fundamentos científicos cuya finalidad es la institución de un nuevo (y mejor) orden, un trabajo que necesariamente supone la contención 0 , más aún, la eliminación de cualquier factor subversivo, el racismo se ajustaba a la visión del mundo y a los métodos de la modernidad" (Bauman 1997, 94). Esta tesis implica que el racismo dejaría de ser un fenómeno marginal para convertirse en una matriz fundamental de la construcción de las relaciones sociales en las sociedades burguesas capitalistas, matriz que resulta reconocible en realidades y procesos sociales diferentes como el racismo biologicista del siglo XVIII, la colonización europea del Tercer Mundo, el genocidio judío, los sistemas de apartheid o determinadas políticas migratorias.

Dicha matriz se caracteriza por la construcción de una alteridad radical, ya se defina ésta de manera genética, étnica o cultural, construcción que se sirve de dos mecanismos fundamentales, la selección y la clasificación. La atribución proyectiva de propiedades supuestamente definitorias de esa alteridad acompaña los procesos de homogeneización cultural que caracterizan la formación de los estados nacionales modernos y es refuncionalizada en nuevos contextos de descomposición de las identidades nacionales y de fuertes flujos migratorios. Al mismo tiempo la construcción de una alteridad radical se sustenta en algún tipo de naturalización o esencialización de las diferencias, independientemente de que éstas sean consideradas diferencias de carácter biológico o cultural ${ }^{1}$. La naturalización apunta a una incompatibilidad insuperable, que no deja otra alternativa que la estricta separación, la subordinación o la aniquilación. Estas prácticas se le- 
gitiman gracias a que la construcción de la alteridad, la significación del otro, posee un carácter de menosprecio e inferiorización que anula toda reciprocidad.

\section{Algunos apuntes SOBRe limitaciones E INSUFICIENCIAS}

Como hemos visto, la investigación psicosocial centra su mirada en los procesos psicodinámicos individuales. Este enfoque corre varios peligros que conviene señalar. En primer lugar el de convertir el racismo y la xenofobia en expresiones de patologías individuales y no en fenómenos sociales globales. La patologización puede contribuir, en segundo lugar, a su marginalización, es decir, a generar una impresión de excepcionalidad o limitación y de esa manera reducir su significación social. Sin embargo, para la masiva producción y reproducción de los prejuicios, así como para su enorme extensión, este enfoque psicosocial no puede señalar en última instancia otro origen que un proceso ahistórico y asocial de elaboración de los conflictos psíquicos y afectivos. Por eso pareciera que una terapia individual podría ser una respuesta adecuada y suficiente al problema del racismo y la xenofobia, pues haría menos vulnerables a los individuos frente a esa forma distorsionada de hacer frente al encuentro con los diferentes que sirve de ocasión para despertar el fondo reprimido de conflictos psicodinámicos mal resueltos, al mismo tiempo que le ofrece una falsa salida. Esto daría prioridad al cambio de planteamientos subjetivos frente a la transformación de las relaciones sociales.

Da la impresión de que en este enfoque lo social sólo está presente como contexto que potencia o reprime, pero siempre actúa desde fuera. Además la construcción social del extraño queda parcialmente velada. Esto tampoco es satisfactoriamente resuelto por aquellos enfoques de psicología social que incorporan la formación de los grupos y su papel en la construcción de la identidad social de los individuos. Ciertamente estos enfoques permiten describir los mecanismos generales de los procesos grupales, pero carecen de capacidad para desentrañar los presupuestos sociales de su génesis. Lo social se agota en presentar la percepción, la valoración y el comportamiento de los individuos como determinados por su pertenencia a un grupo. Ninguno de los dos tipos de enfoque escapa a una cierta antropologización y, por esa vía, a una naturalización. La forma de pensar y actuar xenófoba estaría propiciada por una especie de etnocentrismo universal que se sustenta en mecanismos psíquico-libidinales de alcance general o en procesos de diferenciación y clasificación inevitables en la formación de cualquier grupo humano.

Algunos de estos problemas quedan atajados por el enfoque del análisis del discurso y de crítica de las ideologías, puesto que en él los procesos de construcción del extraño se vinculan con el afianzamiento de las relaciones sociales de dominación. En línea con los planteamientos de M. Foucault, los elementos cognitivos, emocionales, actitudinales, etc., que constituyen el racismo y la xenofobia forman parte de procesos sociales que se reproducen $y$ perpetúan a través del comportamiento y las actitudes individuales. Sin embargo, su entrelazamiento y su interacción quedan sin analizar y sin articular por medio de una consistente teoría de la sociedad. El rechazo de una relación deductiva de las formaciones ideológicas o de los discursos respecto a las condiciones estructurales permite eludir una afirmación dogmática del primado de las relaciones de producción sobre las construcciones ideológicas, pero el concepto de poder se difumina en una relación de dominancia que escasamente hace justicia a la relación mediadora y mediada entre individuo y sociedad, entre la realidad objetiva que ejerce la coacción y la posibilidad objetiva de libertad individual. Se necesita de una crítica completamente formulada de la sociedad, capaz de desentrañar críticamente la relación entre individuo y sociedad en el horizonte de unas relaciones capitalistas-burguesas. Es preciso aclarar cómo cristalizan los procesos sociales globales en la configuración psíquico-libidinal de los individuos y sus representaciones y percepciones en la vida cotidiana, así como la manera en que están imbricadas la dimensión ideológica y la dimensión estructural.

\section{Aportaciones de la teoría crítica DEL ANTISEMITISMO}

\section{a) Semejanzas y diferencias entre racismo y antisemitismo}

El antisemitismo es el odio irracional a los judios ${ }^{2}$ que se expresa en una serie de prejuicios respecto a ellos y

ARBOR Vol. 188755 mayo-junio [2012] 591-604 ISSN: 0210-1963 
se localiza en el ámbito de los discursos y las opiniones, pero puede adoptar formas de rechazo y agresión más radicales, desde su expulsión de posiciones y espacios sociales, económicos o políticos, hasta las acciones puntuales o sistemáticas de aniquilación y exterminio (progromo o genocidio). Estas formas de agresión extrema lo distinguen de otros fenómenos como el racismo o la xenofobia contra minorías. Pero la estructura es en ambos fenómenos, según Adorno, la misma (Adorno 1962, 374). Dicha estructura es reconocible en su carácter de "medio de masas" que "conecta con impulsos libidinales, conflictos, inclinaciones y tendencias, a los que refuerza y manipula, en vez de hacerlos conscientes y clarificarlos" (Adorno 1962, 366). Desde este punto de vista, en la medida en que posee un carácter estructural, el antisemitismo presenta rasgos que lo hacen relativamente independiente del objeto sobre el que se proyecta y que no se sustentan en características atribuibles de modo objetivo a sus víctimas ${ }^{3}$. Posee un carácter funcional en relación con los mecanismos psíqui$\cos$ y sociales que regulan la vida de los individuos y los grupos ${ }^{4}$. Esto permite proyectar esas mismas estructuras sobre otros objetos y vuelve relevante su interpretación para analizar otras formas de prejuicio.

Quizás resulta excesiva la afirmación de Taguieff, según el cual "el neorracismo cultural puede ser considerado en un determinado sentido como una generalización de la judeofobia moderna" (Taguieff 1991, 246), pues este planteamiento amenaza con eliminar las diferencias entre antisemitismo y el nuevo racismo de cuño culturalista ${ }^{5}$. Pero no convendría pasarla sin más por alto, pues tanto el antisemitismo como el racismo se han convertido en recursos flexibles para la construcción de imágenes de lo extraño, diferente, opuesto y hostil (Messerschmidt 2010; Scherschel 2006). En el antisemitismo Taguieff subraya el desplazamiento de un planteamiento puramente biologicista hacia la convicción de que los judíos no son asimilables. Esto vendría a reflejar las dificultades del racialismo puro para sustentar sobre él discriminaciones con soporte jurídico (Benz 2004, 16), pero también se conllevaría mejor con las fantasias antisemitas de una conjura invisible y actuando en la sombra que convierte la amenaza judía en ubicua. En ese desplazamiento coincidiría con el racismo "diferencialista", que ya no defiende tanto unas diferencias biológicas, cuanto el carácter insuperable de las diferencias culturales. En este racismo de nuevo cuño el rechazo del otro se realiza en nombre del respeto a la diferencia, que justifica la animadversión contra cualquier contaminación o mestizaje con tradiciones y formas de vida distintas. Paradójicamente, sobre la base de la inconmensurabilidad radical de las diferentes culturales, defendida en parte por los antirracistas y antiasimilacionistas, se valora a los individuos y los grupos según su supuesta capacidad o incapacidad para asimilarse, para fundamentar la segregación y, en su caso, la expulsión en razón de la demostrada o supuesta incapacidad (San Román 1996).

También Balibar, que intenta dar respuesta a una supuesta inactualidad del racismo biologicista en su definición de neorracismo, subraya que dicho neorracismo no es tan reciente como podría parecer a primera vista. Para ello se apoya en una caracterización del antisemitismo moderno como racismo racial-culturalista. En la segregación racista del "judío" los rasgos somáticos no tienen un papel exclusivo ni preponderante:

"El antisemitismo moderno, el que empieza a cristalizar en la Europa de la llustración [...] ya es un racismo 'culturalista'. Es cierto que los estigmas corporales ocupan un lugar importante en sus obsesiones, pero más bien como signos de una psicología profunda, de una herencia espiritual antes que biológica. [...] El antisemitismo es 'diferencialista' y en muchos aspectos se puede considerar todo el racismo diferencialista actual, desde el punto de vista de la forma, como un antisemitismo generalizado" (Balibar/Wallerstein 1991, 40s.)

Sin embargo, es preciso distinguir claramente entre el antisemitismo y el racismo $u$ otras formas de rechazo étnico/cultural. A pesar de las analogías entre lo que podría denominarse un "antisemitismo secundario o democrático" y un "racismo culturalista o democrático" (Messerschmidt 2010, 98ss.) ${ }^{6}$, ambos no son en absoluto idénticos (Stender 2000). Este último sirve para sustentar en diferencias étnico-culturales un sistema de discriminación que pasa por el vínculo entre diferenciación e inferiorización (Wieviorka 1992, 112). Cuanto mayor es la desigualdad social sustentada en diferencias étnicas o culturales, tanto más encuentra aplicación el prejuicio racista o xenófobo, y esto permite una gran diversidad y estratificación en su aplicación sobre los distintos grupos dependiendo de dicha desigualdad. La cuestión clave es el vínculo entre prejuicio, prácticas de discriminación o exclusión y poder diferenciado. En el marco de la sociedad capitalista el 
racismo y la xenofobia producen una desvalorización de sus víctimas que consagra su inferioridad, mientras que el antisemitismo se dirige contra una sobrevaloración alucinada. El antisemitismo va más allá de la acentuación de lo extraño y su rechazo en el marco de un esquema binario amigo-enemigo. Como ha señalado K. Holz (2001; 2005, 30ss.), en su extrañeza inquietante y maligna "el judio", percibido como "antagonista racial", representa el contrapunto absoluto del principio nacional constitutivo de los estados modernos. Por eso la violencia antisemita apunta a la aniquilación total y no queda satisfecha con la mera asimilación o la subordinación discriminadora.

Sin embargo, estas diferencias no deberian ser excusa para pasar por alto que la formación de prejuicios y estereotipos xenófobos responde al mismo mecanismo proyectivo al servicio de la represión psíquica que actúa en el antisemitismo. Ese mecanismo inconsciente consiste en aislar, separar, externalizar y fijar en personas percibidas 0 señaladas como apropiadas para ello elementos desagradables o experimentados como destructivos en uno mismo. Lo reprimido e inconsciente es trasladado a otro sujeto convertido en objeto de la proyección o creado como tal objeto. Una vez localizado fuera del sujeto y deformado, lo reprimido es percibido como un peligro exterior real. La efectividad de este mecanismo depende de que nunca se haga consciente, sólo así pueden las propias tendencias desagradables aparecer como amenazas externas reales. De esta manera se hacen posibles dos cosas aparentemente contrapuestas e irreconciliables, someterse a las exigencias superyoicas (adaptación a la norma social) y dar rienda a los impulsos agresivos reprimidos (rebelión) (Adorno 1955b, 232). "Los impulsos que no son admitidos como propios por el sujeto, y sin embargo son suyos, se atribuyen al objeto, a la víctima futura" (Horkheimer/Adorno 1968 [1947], 211). El odio contra ésta es un odio a sí mismo o a partes de sí mismo identificadas/proyectadas de modo inconsciente en el objeto convertido en enemigo externo. Gracias a esta identificación proyectiva la agresión puede disfrazarse como autodefensa. Para transformarse en odio colectivo, el miedo, que tiene una raíz psicológica, pero una génesis y una mediación social, necesita de un objeto definido primero como extraño, después como enemigo $y_{\text {, }}$ por fin, como víctima.

Todo esto no viene sino a confirmar la importancia del análisis de las estructuras psico-sociales del prejuicio analiza- das por la Teoría Crítica en relación con el antisemitismo para llevar a cabo un análisis crítico del racismo y la xenofobia en el nuevo horizonte de migraciones globales ${ }^{7}$.

\section{b) El antisemitismo y las estructuras psico-sociales del prejuicio}

La disposición para los prejuicios antisemitas tiene que ver con estructuras psico-sociales que Adorno analiza bajo la figura del "debilitamiento del yo" (Adorno 1961, 580). La interiorización de la dominación social, que se manifiesta en la identificación con el colectivo social, se presenta en los individuos en forma de conflicto psíquico. El análisis de los mecanismos y esquemas que intervienen a la hora de afrontar ese conflicto y los efectos que tienen sobre el conocimiento y la voluntad de los individuos bajo las actuales condiciones de socialización constituyen, según Adorno, el objeto de una sociología reforzada con el análisis psicoanalítico (Adorno 1959, 147). Dicho análisis conduce a la identificación del "carácter autoritario" y el "narcisismo herido" como formas de interiorización de la dominación y expresión del deterioro de la capacidad de reflexión objetiva sobre las propias condiciones sociales de vida.

El interés por la autonomía y la posibilidad de afirmación de sí mismo que representa el yo se encuentran en conflicto directo con las exigencias sociales de adaptación, que es el precio para asegurar la autoconservación. Si no quiere ser expulsado del engranaje social, el individuo tiene que acatar las reglas de juego que dicta la situación dominante, pero las exigencias que se derivan de este acatamiento van asociadas a renuncias que ya no son razonables a primera vista. Ante esto caben dos posibilidades: enfrentarse de modo consciente a la represión social poniendo en peligro la autoconservación o poner en marcha maniobras de suavización y pacificación que impidan tener que soportar grandes mermas de la autoestima o eviten poner en peligro la propia supervivencia. Adorno considera que esta segunda forma es la predominante.

Una manifestación de esta manera de "resolver" el conflicto es el carácter autoritario. Su núcleo no es otro que la ambivalencia entre sometimiento y rebelión coagulada en el psiquismo de los que se aferran al orden existente. Dicho carácter les permite dar una salida al conflicto interior identificándose con el dominio encarnado en una figura personal y proyectando la agresión contra grupos identifi- 
cados como más débiles. Partiendo del análisis freudiano, es posible explicar por qué el carácter autoritario tiene que dirigir la agresión contra grupos considerados extraños. Su debilidad le impide dirigirla contra las autoridades del propio grupo. El conflicto intrapsíquico se proyecta sobre la relación entre el propio grupo y los grupos declarados ajenos, lo que permite la descarga de la agresividad y la identificación con la autoridad. El resultado es una paradójica "rebelión conformista": una especie de combinación entre el placer de obedecer y la agresión contra los indefensos.

También encontramos la misma necesidad de identificación con la autoridad o con el colectivo en el "narcisismo herido", que no es simplemente una figura históricamente posterior al carácter autoritario. Su clave está en el conflicto entre la necesidad de una ocupación libidinal de la propia persona y el agravio permanente que las condiciones sociales para asegurar la autoconservación infringen a los individuos. Dichas condiciones son percibidas como ajenas, extrañas o destinales y, al mismo tiempo, como precarias, cuando no asociadas a insuficiencias de los propios sujetos amenazados, pero raramente identificadas como resultado de coacciones sistémicas. Si las exigencias de autoconservación reclaman una ocupación libidinal adicional de la propia persona (narcisismo), la incapacidad de controlar las condiciones de existencia provocan un agravio permanente que abre y reabre la herida narcisista: "El yo experimenta [...] su impotencia real como agravio narcisista" (Adorno 1955a, 72). La solución a este conflicto se produce a través de la colectivización del yo gracias a la identificación compartida. El narcisismo dañado encuentra cumplimiento en el narcisismo colectivo. La solución de la herida narcisista en el narcisismo colectivo viene exigida, en cierto modo, por el sistema. La ofuscación que le es propia consiste en contribuir a que los sujetos interpreten su debilidad como fuerza (del colectivo), lo que no hace más que aumentar su debilidad.

En el antisemitismo se expresa pues la ilusión fatal de poseer poder, de conocer aparentemente las causas de la opresión y de poder personificar y eliminar al causante de esa opresión. No sólo en los antisemitas, también en el resto de miembros de la sociedad dominan las disposiciones caracterológicas autoritarias y agresivas y las mentalidades esteropáticas. El análisis de Adorno y Horkheimer está referido a la génesis de la disposición estructural para el autoritarismo y el antisemitismo a partir del progreso social de la pérdida de relaciones, es decir, a partir directamente de la dialéctica de la constitución social de los individuos, de la dominación creciente y la adaptación exigida coactivamente. Así pues, el antisemitismo no sería un subproducto de la modernidad, sino que se desarroIlaría con el autoritarismo que caracteriza la modernidad misma.

\section{c) Xenofobia, fobotipos e inmigración}

Como acabamos de ver, en el centro de la investigación sobre el autoritarismo de la Teoría Crítica se encuentra el análisis de las estructuras del resentimiento subjetivo, de sumisión autoritaria y de compensación del narcisismo herido que resultan de las formas de socialización moderna, cuya conceptualización se basa fundamentalmente en una conjunción de teoría psicoanalítica del sujeto y teoría materialista de la sociedad. Con este planteamiento conecta el concepto de "religión de andar por casa" (Alltagsreligion) acuñado por D. Claussen (1995), que se refiere a la peculiar forma de conciencia derivada del conformismo moderno y que responde a la menesterosidad narcisista de los individuos. Con ese concepto se designan los sistemas que ofrecen orientación y orden en la cotidianidad dando respuestas claras y sencillas a las cuestiones sobre el sentido de la vida y que por eso permiten también organizar la relación entre la imagen de sí mismo, la de los extraños y la de los enemigos, y adaptarla a nuevas situaciones.

"La religión de andar por casa demuestra su superioridad frente a los desagradables conocimientos que proporciona el pensamiento por medio del milagro que brinda a sus adictos ya observado por Karl Mannheim: les proporciona el sentimiento de ser al mismo tiempo miembros de una mayoría y de una élite. Para realizar este milagro se sirve de formas de agresión generadoras de comunidad que provienen de la historia de la sociedad europea, esto es, agresión contra los otros y los extraños que se corresponde con el amor hacia lo propio. Xenofobia, antisemitismo, racismo, nacionalismo y antiintelectualismo son sus elementos" (Claussen 1994, 21s.).

Los conceptos que en un determinado momento aparecen en los discursos públicos o en los medios de comunicación sirven para la definición de un "nosotros" frente a los "otros" y para la separación y demarcación de ambos 
grupos, en definitiva para la segregación del "extraño" al servicio de la certeza de lo propio. Los que participan en la construcción de estos conceptos no son muchas veces conscientes de que se trata de "definiciones" y no de diferencias casi "naturales". Dentro del "nosotros" se presupone una homogeneidad ficticia y se espera conformidad con la misma. Sin embargo, los criterios a la hora de trazar la línea de separación pueden cambiar y cambian de hecho. Seres humanos y grupos se vuelven extraños en un sentido radical por medio de una extrañeza construida, atribuida e institucionalizada que conduce a una percepción dramatizada y generalizada de las diferencias con consecuencias fatales. Esto hace que en la cotidianidad los otros sujetos sean percibidos reductoramente como portadores de rasgos culturales étnicos o religiosos estereotipados.

En la actualidad, bajo las condiciones que establecen los cambios económicos, políticos e ideológicos acelerados, estamos asistiendo tanto en las ciencias sociales como en los medios de comunicación a una creciente etnificación y culturalización de los conflictos sociales. Etnia y cultura se han convertido en categorias dominantes tanto en el discurso científico como en el discurso mediático. Se ha impuesto un nuevo culturalismo, es decir, una percepción étnico-religiosa de la vida cotidiana, de las relaciones sociales y de los conflictos internacionales. Si en el orden internacional la tesis de Huntington sobre el "choque de civilizaciones" ha servido para recomponer el esquema "amigo-enemigo" tras el final de la guerra fría, tesis como la de G. Sartori (2002) sobre pluralismo, multiculturalismo y extranjería han venido a ofrecer un marco interpretativo de los supuestos conflictos culturales y políticos entre la población de los países receptores de inmigración y aquellos grupos de inmigrantes que presentan características étnicas, culturales y religiosas divergentes de las de la mayoría de dicha población.

La estrategia argumentativa de G. Sartori ha consistido en colocar a los inmigrantes, sobre todo musulmanes, fuera del espacio de pluralismo y tolerancia que supuestamente caracteriza a las sociedades democráticas. Según él, la historia política y cultural del occidente moderno ha realizado un recorrido desde la intolerancia a la afirmación positiva de la diversidad, pasando por la tolerancia y el respeto del disenso, con el efecto final de un frágil equilibro entre la afirmación de la diversidad y el disenso, por un lado, y la búsqueda de la paz intercultural, por otro. Es esta paz la que se ve ahora amenazada por los "abiertos y agresivos enemigos culturales", por aquéllos que presuntamente atacan el pluralismo con su resistencia a la integración en el marco del pluralismo democrático y que deben ser vistos por ello como "contraciudadanos". Esta estrategia argumentativa apunta a la identificación de unos colectivos concretos como "enemigos culturales" y como "inintegrables", como incompatibles con el marco político democrático y pluralista, estrategia que parece llamada justificar su exclusión precisamente de los derechos que ese marco debe garantizar.

En definitiva se trata de construir un fobotipo que permite estabilizar el vigente sistema de dominación social mediante el desplazamiento de las agresiones sociales. Bajo una perspectiva de observación constreñida se focaliza la mirada en las identidades de determinadas minorías, en vez de en las relaciones sociales dentro de las que el discurso xenófobo cumple su función. Resulta llamativo como en este contexto los estereotipos generados en torno a los musulmanes muestran ciertas semejanzas a los creados por el antisemitismo. En primer lugar la idea de que son extraños a nosotros, no pertenecen a nuestra sociedad por más que vivan entre nosotros. También la creencia de que los musulmanes son identificables por rasgos externos, que tienen intenciones ocultas y persiguen metas no claras, que están vinculados con poderes de fuera, que se apoderan de nuestras pertenencias y tienen creencias completamente ajenas a nosotros (Messerschmidt 2010,97).

No es necesario subrayar el potencial destructivo de este mecanismo de proyección y su capacidad de instrumentalización política, capaz llegado el caso de apropiarse de modo criminal de la espiral de miedo, odio y destructividad. Sin embargo, el marco social no sólo actúa a posteriori instrumentalizando un mecanismo intrapsíquico, sino que, como hemos apreciado en el antisemitismo, la efectividad de éste responde a un debilitamiento de yo, cuyo origen es de carácter social. Si una cierta proyección identificadora, lo mismo que un cierto etnocentrismo, resultan inevitables y pueden ser vistos como una constante antropológica, la incapacidad para elevarlos a conciencia y hacerlos reflejos, desactivando así su potencial destructivo, posee un origen social y depende de unas determinadas condiciones sociales de reproducción de la existencia en el sistema capitalista. Por eso no conviene ser víctimas de fáciles recetas sociopedagógicas frente a la xenofobia o el racismo. 
La distorsión perceptiva que acompaña a la proyección páthica se muestra resistente frente a nuevas experiencias y no resulta fácilmente transformable por medio de ellas, pues responde a unas necesidades de la economía psíquico-libidinal de los individuos socializados en unas determinadas condiciones, que se mantienen estables o se siguen reproduciendo mientras dichas condiciones no varien.

Por todo esto, resulta necesario actualizar la contribución de la Teoría Crítica al análisis del antisemitismo para un desentrañamiento de las claves de la actitud xenófoba que se ha vuelto ubicua en Europa, un desentrañamiento que haga verdadera justicia a la importancia de este fenómeno. Esa actitud se alimenta de prejuicios profundamente arraigados, que han sido adquiridos en un largo proceso de socialización y educación y que son actualizados y reforzados por un profundo sentimiento de inseguridad y amenaza ante un capitalismo neoliberal que actúa a escala mundial con una contundencia despiadada. Los individuos se ven confrontados con una exigencia de completa flexibilidad y movilidad que posee un efecto enormemente desestabilizador y genera miedos existenciales, provoca inseguridad al cuestionar todos los ámbitos de vida y prepara así el caldo de cultivo para los mecanismos de amurallamiento frente al extraño y la búsqueda de chivos expiatorios, para la xenofobia y, finalmente, para la violencia de extrema derecha. El valor de la aportación de la Teoría Crítica respecto al antisemitismo en este contexto es que impide analizar todos estos fenómenos como coyunturales o marginales, dotándoles de una significación central para el desentrañamiento de la constitución social de los individuos en las sociedades modernas.

Parafraseando una conocida afirmación de M. Horkheimer, quien no quiera hablar de las condiciones sociales que convierten los procesos de subjetivación en procesos cada vez más precarios y que vuelven a los individuos cada vez más vulnerables, debería callar sobre xenofobia y racismo.

\section{NOTAS}

* Este artículo se inserta en el Proyecto de Investigación "Filosofía después el Holocausto: vigencia de sus lógicas perversas" financiado por el Plan $\mathrm{Na}$ cional I+D+i del Ministerio de Ciencia e Innovación (FFI2009-09368). Es la reelaboración y ampliación de una ponencia que con el título "Teoría del antisemitismo y xenofobia: la violencia del prejuicio" expuse en las III Jornadas sobre Políticas Migratorias, Justicia y Ciudadanía, organizadas en el Instituto de Filosofía del CSIC (Madrid) del 27 al 29 de octubre de 2010

1 Para Stuart Hall la naturalización es el rasgo esencial del racismo y define su carácter ideológico: "Los racismos deshistorizan -traducen estructuras históricamente específicas en un lenguaje atemporal de la naturaleza; descomponen las clases en individuos y reúne a estos individuos desagregados en unidades reconstruidas de nuevo, en formaciones coherentes, en nuevos 'sujetos' ideológicos: traducen las 'clases' en negros y 'blancos', grupos económicos en 'pueblos', fuerzas consistentes en 'razas.'" (Hall 1994, 135).

2 Evidentemente el término "judío" en un contexto de análisis del antisemitismo siempre debe ser leido con la reserva correspondiente. No prejuzga la existencia de una identidad claramente definida y delimitada, y menos una que responda a la construcción proyectiva de los antisemitas. En este sentido pueden ser ilustrativas las reflexiones que realiza J. Derrida en torno a la identidad judía en Derrida 2003 (cf. Zamora 2007, 32ss.).

3 Éste es el sentido de las palabras de Horkheimer y Adorno respecto a que el "antisemitismo fascista en cierto modo ha de fabricar previamente su objeto" (Horkheimer/Adorno 1968 [1947], 232).
Recibido: 2 de diciembre de 2011 Aceptado: 21 de diciembre de 2011 
4 El carácter maníaco (paranoico) y su potencial destructivo exige reflexionar sobre la relación entre la patología individual y la colectiva, así como sobre el efecto normalizador de esta última respecto a la primera, lo que explicaría que sólo algunos de los sujetos desarrollen sintomas clínicos. La proyección "páthica" es movilizada sistemáticamente por la política de tal modo que "el objeto de la enfermedad es determinado de forma ajustada a la realidad" y "el sistema de delirio se convierte en norma racional en el mundo" (Horkheimer/Adorno 1968 [1947], 211). Éste es probablemente el motivo de que Adorno denomine el mecanismo psicosocial de la proyección paranoica antisemita páthico y no pathológico. Estamos ante un padecimiento a través de la sociedad y por su causa que responde al esquema del "malestar de la cultura" (Freud) y no debe interpretarse según los criterios de la doctrina psiquiátrica de la enfermedad. Lo páthico designa en Adorno la "enfermedad de los normales" adaptada a su época (cf. Pohl 2010, 63s.).

5 Para una reconstrucción histórica de las relaciones entre racismo y antisemitismo, cf. Giesen 1997.

6 Sobre el sentido de estos conceptos, cf. Bergmann 2006; Holz 2005; Claussen 1987, y Rensmann 1998.

7 La recuperación de la Teoría Crítica en este nuevo contexto está presidida por una división del trabajo inapropiada: se asignan los estudios empíricos sobre la "personalidad autoritaria" a la investigación psico-social y los "Elementos del Antisemitismo" de la Dialéctica de la llustración a la filosofía o a la teoría social, cuando en realidad ambos trabajos se realizaron simultáneamente durante el exilio y están vinculados entre sí. En la colabora- ción de Max Horkheimer y Theodor W. Adorno que fructificaría en la Dialéctica de la Ilustración (Horkheimerl Adorno 1968 [1947]) y en el proyecto de investigación interdisciplinar sobre la Personalidad Autoritaria (Adorno et al. 1950; Adorno 1995), en el que participó Adorno, se investigó el antisemitismo y el autoritarismo tanto desde la perspectiva teórica como desde la perspectiva empírica.

\section{BIBLIOGRAFÍA}

Adorno, Th. W.; Frenkel-Brunswick, E.; Levinson, D. J. y Sanford, R. N. (1950): The Authoritarian Personality, New York, Evanston, London.

Adorno, Th. W. (1955a): "Zum Verhältnis von Soziologie und Psychologie", en Gesammelte Schriften, t. 8, Frankfurt, a.M.: Suhrkamp, 42-85.

Adorno, Th. W. (1955b): "Schuld und Abwehr. Eine qualitative Analyse zum Gruppenexperiment", en Gesammelte Schriften, t. 9, Frankfurt, a.M.: Suhrkamp, 121-324.

Adorno, Th. W. (1959): "Aberglaube aus zweiter Hand", en Gesammelte Schriften, t. 8, Frankfurt, a.M.: Suhrkamp, 147-176.

Adorno, Th. W. (1961): "Meinung Wahn Gesellschaft", en Gesammelte Schriften, t. 10, Frankfurt, a.M.: Suhrkamp, 573-594.

Adorno, Th. W. (1962): "Zur Bekämpfung des Antisemitismus heute", en Gesammelte Schriften, t. 20, Frankfurt, a. M.: Suhrkamp, 360-383.

Adorno, Th. W. (1995): Studien zum autoritaren Charakter, Frankfurt, a.M.: Suhrkamp.

Allport, F. H. (1954): The Nature of Prejudice, Cambridge, Ma.: Addison-Wesley.

Álvarez, I. (2002): "La construcción del inintegrable cultural", en J. de Lucas y
F. Torres (eds.), Inmigrantes: ¿Cómo los tenemos?, Madrid: Talasa, 169-195.

Balibar, E. y Wallerstein, I. (1991): Raza, nación y clase, Madrid: IEPALA.

Barcellona, P. (2000): "El vaciamiento del sujeto y el regreso del racismo", en H. C. Silveira Gorski (ed.), Identidades comunitarias y democracia, Madrid: Trotta, 113-126.

Bauman, Z. (1997): Modernidad y Holocausto, Madrid: Sequitur.

Benz, W. (2004): Was ist Antisemitismus?, München: C. H. Beck.

Bergmann, W. (2006): "Erscheinungsformen des Antisemitismus in Deutschland heute", en B. Fechler et al. (eds.), Neue Judenfeindschaft?, Frankfurt, a.M.: New York: Campus, 33-50.

Bonilla-Silva, E. (2006): Racism Without Racists (2. ${ }^{\text {a }}$ ed.), Lanham, MD: Rowman and Littlefield.

Bralo, Z. y Morrinson, J. (2005): "Immigrants, refugees and racism", en Guild, E. y Van Selm, J., International migration and security opportunities and challenges, London and New York: Routledge Taylor \& Francis Group, 113-128.

Braum, Ch. y Ziege, E. V. (2004): Das "bewegliche" Vorurteil, Würzburg: Königstein und Neumann.

Cea D'Ancona, M. ${ }^{a}$ A. (2008): Evolución del racismo y la xenofobia en España, Madrid: Ministerio de Trabajo e Inmigración.

Claussen, D. (1987): Grenzen der Aufklärung, Frankfurt, a.M.: Fischer.

Claussen, D. (1994): "Veränderte Vergangenheit", en Id., Grenzen der Aufklärung,

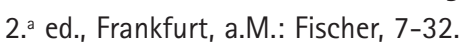

Claussen, D. (1995): "Die Banalisierung des Bösen", en M. Werz (ed.), Antisemitismus und Gesellschaft, Frankfurt a.M: Neue Kritik, 13-28.

Colectivo IOÉ (2005): "Ciudadanos o intrusos: la opinión pública española ante los inmigrantes", en Papeles de Economía Española, 104, 194-209. 
Derrida, J. (2003): "Abraham, l'autre", en J. Cohen y Zagury-Orly (eds.), Judéités. Questions pour Jacques Derrida, Paris: Galilée, 11-42.

European Union Agency For Fundamental Rights (2010a): Annual Report 2009, European Union (http://fra.europa.eu).

European Union Agency For Fundamental Rights (2010b): Annual Report 2010-Conference Edition, European Union (http://fra.europa.eu).

Fanon, F. (1980 [1961]): Los condenados de la tierra, 2. a ed., 6. reimp, México: FCE.

Giesen, B. (1997): "Antisemitismus und Rassismus", en M. Dabag y K. Platt (eds.), Genozid und Moderne, vol. 1, Opladen: Leske + Budrich, 206-240.

Hall, S. (1978): "Racism and reaction", en Five Views of Multi-Racial Britain, London: Commission for Racial Equality, 23-35.

Hall, S. (1980): "Race, Articulation and Societies Structured in Dominance", en UNESCO, Sociological Theories: Race and Colonialism, París: UNESCO, 305-345.

Hall, S. (1989): "Rassismus als ideologisher Diskurs", en Das Argument, n. ${ }^{\circ} 178$, 913-922.

Hall, S. (1994): Rassismus und kulturelle Identität, Hamburg: Argument.

Hall, S. (1996): "Gramsci's relevance for the study of race and ethnicity", en D. Morley y K. H. Chen (eds.), Stuart Hall: Critical Dialogues in Cultural Studies, London: Routledge, 411-440.

Holz, K. (2001): Nationaler Antisemitismus, Hamburg: Hamburger Edition.

Holz, K. (2005): Die Gegenwart des Antisemitismus, Hamburg: Hamburger Edition.

Horkheimer, M. y Adorno, Th. W. (1968 [1947]): Dilektik der Aufkärung, Amsterdam, Querido Verl. (cit. por Th. W. Adorno, Gesammelte Schriften, Frankfurt, a.M.: Suhrkamp 1981).

Klinger, C. y Knapp, G. A. (ed.) (2008): Über-Kreuzungen. Fremdheit, Unglei- chheit, Differenz, Münster: Westfälisches Dampfboot.

Lucas, J. de (2002): "Algunas propuestas para comenzar a hablar en serio de política de inmigración", en J. de Lucas y F. Torres (eds.), Inmigrantes: ¿cómo los tenemos?, Madrid, Talasa: 23-48.

Memmi, A. (1982): Le racisme: description, définition, traitement, Paris: Gallimard.

Messerschmidt, A. (2010): "Flexible Feindbilder - Antisemitismus und der Umgang mit Minderheiten in der deutschen Einwanderungsgesellschaft", en W. Stender, G. Follert y M. Özdogan (eds.), Konstellationen des Antisemitismus, Wiesbaden: Verlag für Sozialwissenschaften, 91-108.

Miles, R. (1993): Racism after 'Race Relations', London: Routledge.

Pohl, R. (2010): "Der antisemitische Wahn", en W. Stender, G. Follert y M. Özdogan (eds.), Konstellationen des Antisemitismus, Wiesbaden: Verlag für Sozialwissenschaften, 41-68.

Poliakov, L.; Delacampagne, Ch. y Girard, P. (1976): Le Racisme, Paris: Seghers.

Reemtsma, J. Ph. (1991): "Die Falle des Antirassismus", en U. Bielefeld (ed.), Das Eigene und das Fremde, Hamburg: Junius, 269-282.

Rensmann, L. (1998): Kritische Theorie über den Antisemitismus, Berlin/Hamburg: Argument.

Said, E. W. (1993): Culture and Imperialism, London: Vintage.

San Román, T. (1996): Los muros de la separación, Madrid: Tecnos.

Sartori, G. (2002): La sociedad multiétnica, Madrid: Taurus.

Scherschel, K. (2006): Rassismus als flexible symbolische Ressource, Bielefeld: transcript.

Silveira Gorski, H. C. (2000): "La vida en común en sociedades multiculturales", en Id. (ed.): Identidades comunitarias y democracia, Madrid: Trotta, 11-43.
SOS Racismo (2008): Informe Anual 2008. Sobre el racismo en el Estado Español, Icaria.

Stender, W. (2010): Antisemitismus, Rassismus, Nationalismus, Hannover (i.V.).

Taguieff, P. A. (1991): "Die Metamorphosen des Rassismus und die Krise des Antirassismus", en Bielefeld, U. (ed.), Das Eigene und das Fremde, Hamburg: Junius, 221-268.

Tajfel, H. y Turner, J. C. (1986): "The social identity theory of intergroup behavior", en S. Worchel y W. Austin (eds.), Psychology of intergroup relations, Chicago: Nelson-Hall, 7-24.

Tarman, Ch. y Sears, D. 0. (2005): "The conceptualization and measurement of symbolic racism", The Journal of Politics, 67 (3), 731-761.

Turner, J. C. (1990): Redescrubrir el grupo social, Madrid: Morata.

Volkov, Sh. (2000): Antisemitismus als kultureller Code, 2. ${ }^{\text {a }}$ ed., München: C.H. Beck.

Wieviorka, M. (1992): El espacio del racismo, Barcelona: Paidós.

Wieviorka, M. (2003): "Diferencias culturales, racismo y democracia", en D. Mato (coord.), Políticas de identidades y diferencias sociales en tiempos de globalización, Caracas: FACESUCV, 17- 32.

Zamora, J. A. (2007): "¿Se puede hablar de un pensamiento judio?", en R. Mate y R. Forster (ed.), El Judaísmo en Iberoamérica, Madrid: Trotta, 25-70.

Zapata-Barrero, R. (2004): Inmigración, innovación política y cultura de acomodación en España, Barcelona: CIDOB.

Ziege, E.-M. (2009): Antisemitismus und Gesellschaftstheorie, Frankfurt, a.M.: Suhrkamp.

Zubero Beaskoetxea, I. (2008): "De la interculturalidad:¿a más'inter'culturalidad?", en C. García (aut.), Retos del siglo XXI, Burgos: S. Publicaciones Universidad de Burgos, 131-142. 